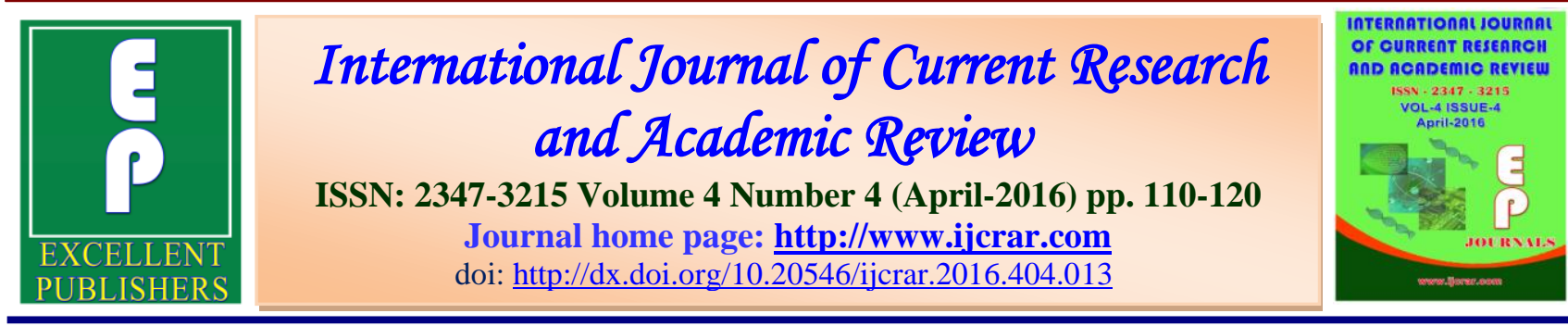

\title{
Hematological, Biochemical and Histopathological Changes by Bisphenol-A in Albino Pregnant Rats
}

\section{T. Geetharathan*}

Department of Biotechnology, Sri Padmavati Mahila Visvavidyalayam, Tirupati-517502, Andhra Pradesh, India

*Corresponding author

\begin{tabular}{|c|c|}
\hline KEYWORDS & A B S T R A C T \\
\hline $\begin{array}{l}\text { Bisphenol-A, } \\
\text { Pregnant rats, } \\
\text { Spleen, } \\
\text { Hematology, } \\
\text { Liver Enzymes }\end{array}$ & $\begin{array}{l}\text { Bisphenol-A (BPA) is a high molecular polymer organic compound widely } \\
\text { used all over the world. The purpose of this study was to investigate the } \\
\text { hematological, biochemical and histological alterations in pregnant rats } \\
\text { induced by BPA which is an estrogenic environmental contaminant. } \\
\text { Pregnant rats were administrated orally BPA ( } 50 \mathrm{mg} / \mathrm{kg} / \text { day.b.wt and } \\
500 \mathrm{mg} / \mathrm{kg} / \text { day.b.wt). After } 9 \text { consecutive days of exposure, blood, sera and } \\
\text { tissues were collected for hematological, biochemical and histopathological } \\
\text { examination. Lymphocytes were separated from the spleen for rosset } \\
\text { formation test. BPA- treated rats showed a significant reduction in red cell } \\
\text { count, hemoglobin concentration and packed cell volume. The serum activity } \\
\text { of alkaline phosphatase, low-density lipoprotein levels showed increased in } \\
\text { BPA-treated groups concomitant with reduction in glucose levels. } \\
\text { Leucogram, E-rosettes forming count and high-density lipoprotein values did } \\
\text { not show significant differences but alter albumin \& globulin levels. } \\
\text { Histopathological alterations were detected in liver and spleen of BPA-treated } \\
\text { rats. From the present study it could be concluded that exposure to BPA is } \\
\text { accompanied with anemia, liver and spleen injuries in pregnant rats. }\end{array}$ \\
\hline
\end{tabular}

\section{Introduction}

Bisphenol-A is a widely produced, endocrine disrupting compound that is pervasive in the environment. It is an estrogenic endocrine disrupting chemical (EDC) which has been utilized extensively in dentistry, food packaging, and lacquers (Colborn et al., 1993). However, BPA has other effects such as inflammatory cytokines dysregulation (Ben-Jonathan et al., 2009) and increase of oxidative stress (Asahi et al., 2010), which is independent of estrogenic activity. More recently, it has been reported that BPA may interfere with and disrupt the immune system via a variety of cytokine signals (Yamashita et al., 2005).Therefore, dysregulation of cytokine signaling can cause a variety of diseases, 
including allergy, autoimmune diseases, inflammation, and cancer (Tamiya et al., 2011). It is omnipresent in the environment and widely distributed and unavoidable. It accumulates in pregnant adult females and its continued exposure during gestation is likely to have an impact on the development of the fetus. The hazardous effects of BPA may lead to heart disease, insulin resistance syndrome, type II diabetes, dyslipidemia, obesity and high blood pressure and spleen toxicity (Elobeid and Allison, 2008; Newbold et al., 2009). Bisphenol-A accumulates in pregnant adult females likely because of accumulation in fat (Fernandez et al., 2007), also is particularly potent during fetal and neonatal development because the liver has limited capacity to deactivate BPA in foetuses and newborns.

Exposure of the developing fetus to BPA is of particular concern as the compound readily crosses the placental barrier and accumulates both in the placenta and in the fetus (Takahashi and Oishi, 2000). Studies have been conducted in 2009 showing association between BPA exposure and oxidative stress, which might contribute to some of its toxic effects (Hong et al., 2009). Few studies have concern the toxic effect of BPA on other tissues and its potential to increase the risk of metabolic disorders (Yildiz, N. and N. Barlas, 2013). Prenatal exposure to BPA has been associated with hormonal, morphological, functional, and behavioral anomalies related to reproduction (Adriani et al., 2003).

Studies have also determined that BPA can be measured in humans in serum, urine, amniotic fluid, follicular fluid, placental tissue, and umbilical cord blood. In some cases, the levels of total BPA (free and conjugated) in human blood and other fluids are higher than the concentrations that have been reported to stimulate a number of molecular endpoints in cell culture in vitro, and appear to be within an order of magnitude of the levels of BPA in animal studies. This study investigated the possible effect of BPA in pregnant rat, following oral administration (dose started gestational day $8^{\text {th }}$ to $\left.15^{\text {th }}\right)$, by examining alterations in the hematological and biochemical parameters. In addition, we evaluated the histopathological alterations in liver and spleen.

\section{Materials and Methods}

Chemicals: Bisphenol-A (Sd Fine Chemicals, Bombay) was dissolved in Sesame oil (vehicle) as stock before administration.

Reagent kits for measuring of alkaline phosphatase (ALP), albumin, glucose, globulin, high-density lipoprotein (HDL) \& Low-density lipoprotein (LDL) were purchased from Sd Fine Chemicals, Bombay.

\section{Animals and Experimental Design}

\section{Experimental Animals}

Pregnant wistar albino rats weighing 250$300 \mathrm{~g}$ were used as experimental animals. The animals were obtained from the M/S Raghavendra Enterprises, Bangalore, India. They were maintained on stock diet and kept under fixed appropriate conditions of housing and handling. Different experimental groups of the animals were caged separately and an average of 6 animals per cage was maintained. The control as well as other treated groups of rats was given free access to standard chow and water ad libitum. All these animals were housed in wooden cages and provided water in glass bottles. 


\section{Experimental Design}

The animals were divided into 3 groups. Animals of group (1) served as control and received a daily oral administration of sesame oil, Animals of group (2) were administered orally $50 \mathrm{mg} / \mathrm{kg}$ of BPA for 9days and group (3) were administered orally $500 \mathrm{mg} / \mathrm{kg}$ of BPA for 9 days respectively. The doses of BPA were administered 9 days (gestational day $8^{\text {th }}$ to $\left.15^{\text {th }}\right)$. The lower dose of BPA $(50 \mathrm{mg} / \mathrm{kg})$ in this study was chosen on the base of previous studies (Bian et al., 2006; Richter et al., 2007).

At the end of the experiment, rats from treated as well as control groups were fasted overnight, weighed and sacrificed on gestational day $15^{\text {th }}$ using a $\mathrm{CO}_{2}$ inhalation chamber. Blood samples were collected with EDTA anticoagulant for haematological examination and without anticoagulant to obtain serum. Liver \& spleen were dissected and weighed in order to calculate the organ/body weight ratios for each animal. Portions of liver $\&$ spleen of each rat were kept in $10 \%$ formalin for the histopathological examination. Spleen was used for lymphocyte separation to evaluate rosette formation test.

\section{Hematological Assays}

Total erythrocyte and leukocytecounts were determined using an improved Neubauer hemocytometer. Packed cell volume (PCV) was estimated by microhematocrit technique. Hemoglobin concentration $(\mathrm{Hb})$ was estimated using Drabkin's method. Differential leukocytic count was done on Giemsa stained blood smears. Mean corpuscular volume (MCV) and Mean corpuscular hemoglobin concentration (MCHC) were calculated according to standard formulas.

\section{Biochemical Analysis of Serum}

Serum albumin was measured (Dumas, B.T. and H.G. Biggs, 1972) in both control and BPA treated groups while the total globulins were determined by subtracting serum albumin value from the value of serum total protein to obtain the albumin-globulin (A/G) ratio. Serum activities of ALP were evaluated in both control and BPA treated groups.

\section{Estimation of Blood Glucose}

Glucose level was estimated according to Trinder, P, 1969.

\section{Serum Lipid Profile}

HDL was estimated by enzymatic colourimetric reaction (Naito, H.K., 1984). Low-density lipoprotein cholesterol (LDL) was estimated by computation according to the methods described by Friedewald et al., (1972).

\section{Erythocyte Rosette Test}

Preparation of Spleen Mononuclear Cell: In pregnant rats, spleen obtained on the end of experiment and washed in $0.15 \mathrm{M} \mathrm{NaC} 1$. Cells from spleen were obtained by grinding the tissue in cold PBS, pH 7.2 and filtering the cells through a mesh. After washing with RPMI 1640 medium, the cells were harvested. Single cell suspensions of the spleen of each rat were maintained in RPMI 1640 medium with $10 \%$ fetal calf serum. Two volumes of the cell suspension were layered onto one volume of Ficoll Hypaque and centrifuged for $25 \mathrm{~min}$ at $1500 \mathrm{xg}$. The mononuclear cells were collected, washed by centrifugation three times with RPMI 1640 containing $10 \%$ fetal calf serum and then adjusted to a concentration of 10 lymphocytes/ $\mathrm{ml}$ in the same medium for 
rosette formation test (Hung, A.L. and S. Lloyd, 1989).

\section{Rosette Formation}

Sheep erythrocytes (SRBC) were collected, washed with PBS by centrifugation at 300 $\mathrm{xg}$ for $5 \mathrm{~min}$ and adjusted to a $1 \%$ suspension The E-rosette test was performed as follows: $500 \mathrm{ul}$ of the purified spleen cells was added to $250 \mathrm{ul}$ of the well mixed $1 \%$ SRBC suspension. The mixture was centrifuged immediately at $250 \mathrm{xg}$ for $2 \mathrm{~min}$ and left to stand overnight at $4^{\circ} \mathrm{C}$. The supernatant was then removed and the pellet gently resuspended with 50 ul of $1 \%$ toluidine blue in PBS. Under light microscope, the number of rosettes counted out of 200 lymphocytes was recorded. Four or more RBCs surrounding a nucleated cell were scored as a rosette.

\section{Histopathological Examination}

Liver and spleen tissues of both groups (control \& BPA treated pregnant groups) were processed and tissue sections were stained with hematoxylin and eosin.

\section{Statistical Analysis}

Statistical analysis was carried out using Statistical Package for Social Sciences (SPSS) software in a PC-compatible computer. Statistical significances of the differences between obtained values (Mean \pm SEM) were determined by Student's t test, $\mathrm{P}<0.05$ was considered statistically significant.

\section{Results and Discussion}

\section{Hematological Assays}

As shown in Table-1, In BPA-treated pregnant rat groups there were a significant reduction in red cell count, $\mathrm{Hb}$ concentration and PCV compared to control. There were significant differences regarding $\mathrm{MCV}$ and MCHC between the control group and the BPA- treated groups. Leucogram values showed no significant changes between the control group and BPA- treated groups.

\section{Clinical Biochemical Assays}

In Table-2, the activities of serum ALP exhibited a significant increase in BPA groups compared to control group. There were significant differences albumin and globulin levels of BPA groups compared to the control group.

LDL values significantly increased in BPAtreated groups while no significant difference in HDL value was noticed in BPA-treated groups compared with the control. On the other hand, significant decrease in glucose levels were observed in the BPA groups compared to the control group.

\section{Histopathological Results}

\section{The Liver Tissue}

The histopathological examination of the liver sections in the control pregnant rat group showed normal histological picture, the liver sections revealed normal lobular architecture with ill-distinct interlobular connective tissue septa (4). Each hepatic lobule consisted of hepatocyte plates radiating from the thin-walled central vein (1). Hepatocytes(5) were large, polygonal cells with acidophilic cytoplasm containing rounded vesicular nuclei (3) and some of them were binucleated. The blood sinusoids (2) separating the hepatocyte plates lined with endothelial cells and von kupffer cells (Fig-1.1). In lower dose of BPA group (50 $\mathrm{mg} / \mathrm{kg}$ ), small central veins (1), hepatic 
plate's (5) disarrangement, dilatation and congestion of blood sinusoids (2) with numerous von kupffer cells were detected. Swollen hepatocytes with severe vacuolar degeneration, beside the different signs of nuclear degenerative changes as karyorhexis and karyolysis, irregular lobular connective septa (4) were recorded (Fig1.2). In higher dose of BPA group (500 $\mathrm{mg} / \mathrm{kg}$ ), hepatic plates (5) are high disarrangement; high dilatation and congestion of blood sinusoids (2) with numerous von kupffer cells were detected. Small central veins (1), Swollen hepatocytes with severe vacuolar degeneration, beside the different signs of nuclear (3) degenerative changes as karyorhexis and karyolysis, highly irregular connective septa (4) were recorded (Fig1.3)

\section{The Spleen Tissue}

The examined spleen sections of lower dose BPA treated pregnant rats showed histological alterations as, increasing in the white pulp area (1) with progressive lymphocytic hyperplasia and hypertrophy of the splenic lymphoid follicles with illdistinct germinal centers (Fig-2.2). In addition, pronounced dilatation and congestion of trabecular splenic blood vessels (4) and splenic sinuses (3) were recorded. Hemosiderosis was increased and clearly distributed throughout the red pulp area (2).

Higher dose BPA treated pregnant rats showed histological alterations as, highly increasing in the white pulp area (1) with progressive lymphocytic hyperplasia and hypertrophy of the splenic lymphoid follicles with ill-distinct germinal centers (Fig-2.3). In addition, highly pronounced dilatation and congestion of trabecular splenic blood vessels (4) and splenic sinuses
(3) were recorded. Hemosiderosis was increased and clearly distributed throughout the red pulp area (2).

The spleen of control rats showed normal histological picture with distinct white pulp (1) and red pulp (2) that covered by a dense fibrous connective tissue capsule emerging trabeculae carrying blood vessels (Fig2.1).The white pulp composed of separated small sized splenic lymphoid follicles containing one or two eccentric central arteries which surrounded by a periarterial lymphoid sheath (PALS). Some of these follicles contain a central lightly stained area (3) called a germinal center which capped by densely stained area called corona or mantle zone. The red pulp consisted of splenic cords and splenic sinuses(4).

Bisphenol-A (BPA) is a widely used industrial plasticizer with known estrogenic properties. It is used in the manufacture of epoxy resins and polycarbonate plastics, which in turn find application in a wide variety of domestic products. Human infants may also be exposed to other environmental estrogens. Bottle fed infants are most likely exposed to BPA. The xenoestrogen BPA has a chemical structure similar to the potent synthetic estrogen diethylstilbestrol (DES), and is found in plastic baby bottles.

In the present study, the number of rosettes forming lymphocytes was unchanged in the lower \& higher dose BPA treated groups as compared to the control group suggesting that BPA did not affect the activity of splenic T-lymphocytes. Yamashita et al., (2003) reported no change in T-cell subpopulations with BPA treatment. Current results showed that oral exposure of pregnant rat to $\mathrm{BPA}$ does significantly reduce the erythrocytes number, $\mathrm{Hb}$ concentration and PCV compared to control values. Exposure to BPA resulted in 
normocytic normochromic anemia. The present findings come in accordance with Uluta et al and Yamasaki and Okuda who evaluated the BPA hematotoxicity in rat at dose of $125 \mathrm{mg} / \mathrm{kg}$ and $100 \mathrm{mg} / \mathrm{kg}$, respectively. They found that BPA induced a significant decrease in red cell count, $\mathrm{Hb}$ concentration and PCV. The decrease in the red blood cells may indicate a disruption of erythropoiesis. The administration of estrogens has been known to reduce erythropoiesis in pregnant rats. The present data of leukogram revealed that BPA did not induce any change in leucocytic count or differential count when compared with the control. Uluta et al reported that BPA at doses of 125 and $250 \mathrm{mg} / \mathrm{kg}$ in rats induce no effect on leucogram.

The liver is a target tissue for endocrinedisrupting chemicals. Specific estrogen receptors exist in the liver and cellular responses involving estrogen interactions have been identified (Zumbado, M., 2002). The current study demonstrates that BPA has adverse effects on the liver in pregnant rats, as indicated by increased activities of ALP enzyme. It is released in the blood stream when the liver is damaged (Henderson, A.R. and D.W. Moss, 2005).Similar elevated levels of serum hepatic enzymes activities were previously observed that resulted from BPA at doses of $50 \mathrm{mg} / \mathrm{kg}$ and $500 \mathrm{mg} / \mathrm{kg}$ in pregnant rats. Hepatic damage induced by BPA may be due to generation of reactive oxygen species in the liver (Korkmaz, A., 2010). The elevated activities of liver enzymes in BPA groups confirm our histopathological findings. In this study, severe alterations were recorded in the liver of higher dose BPA treated rats, which manifested by swollen and vacuolated hepatocytes with nuclear degenerations, dilatation and congestion in the blood sinusoids with increased number of Von Kupffer. In addition, dilatation and congestion of the portal vein with periportal infiltration of inflammatory cells and mild fibrosis were detected. These findings agreed with the results recorded by Daniela-Saveta et al., (2014). BPA administration in pregnant rats reported to increase the hepatic oxidative stress and mitochondrial dysfunction leading to structural changes of rat liver (Eshak, M.G. and H.F. Osman, 2014).

In the current study, lower and higher dose of BPA treated pregnant rats, hypoglycemia was recorded when compared to control. Alonso-Magdalena et al. (2006) found that treatment with BPA at a dose of $10 \mu \mathrm{g} / \mathrm{kg}$ produces an increase in the pancreatic insulin content, a rapid increase in plasma insulin and a decrease in blood glucose.

In the present study, exposure to low doses of BPA increases the insulin expression and production by the pancreas (Nadal, A., et al., 2009). Insulin is known to increase lipogenesis by both post-translational protein modifications and transcriptional mechanisms (Kersten, S., 2001). Kotzka et al. (2004) and Xie et al. (2009), found that activity and expression of sterol regulatory element binding protein 1c (SREBP-1c), which regulates cholesterol metabolism, were activated by increased insulin levels. Thus, insulin is likely to contribute to hypercholesterolemia observed following BPA exposure. However, Marmugi et al., 2012, did not rule out the contribution of other mechanisms, independent of insulin and possibly involving direct effects of BPA on the liver, to the hepatic transcriptional impacts detected in the BPA-treated mice. Asahi et al., (2010) reported that bisphenol induces mitochondria dysfunction and rough endoplasmic damage which in turn important for protein pathway. In addition, BPA treatment impairs glycogen content by decreasing the glycogen phosphorylation and increase glycolysis (Jayashree, S., et al., 2013). 
Int.J.Curr.Res.Aca.Rev.2016; 4(4): 110-120

Table.1 Haematological Analysis and E-rosette Count of Pregnant Rats in the Control and BPA Groups

\begin{tabular}{|c|c|c|c|}
\hline Parameters & Control & BPA 50mg/kg & BPA 500mg/kg \\
\hline Red blood cell $(\mathrm{x} 106 / \mu \mathrm{l})$ & $7.73 \pm 0.11$ & $6.06 \pm 0.27^{*}$ & $4.25 \pm 0.22^{*}$ \\
\hline Packed cell volume \% & $47.67 \pm 1.45$ & $42.67 \pm 0.33^{*}$ & $30.32 \pm 0.22^{*}$ \\
\hline Hemoglobin $(\mathrm{g} / \mathrm{dl})$ & $15.60 \pm 0.21$ & $14.13 \pm 0.20^{* *}$ & $10.12 \pm 0.20^{* *}$ \\
\hline MCV (fl) & $66.64 \pm 1.70$ & $64.46 \pm 2.19$ & $54.14 \pm 2.10$ \\
\hline MCHC $(\%)$ & $32.77 \pm 0.83$ & $33.13 \pm 0.52$ & $44.15 \pm 0.15$ \\
\hline White blood cell $(\mathrm{x} 103 / \mu \mathrm{l})$ & $10.02 \pm 0.49$ & $9.39 \pm 0.54$ & $9.30 \pm 0.12$ \\
\hline Lymphocyte $(\mathrm{x} 103 / \mu \mathrm{l})$ & $7.46 \pm 0.32$ & $7.08 \pm 0.06$ & $6.14 \pm 0.66$ \\
\hline Neutrophil $(\mathrm{x} 103 / \mu \mathrm{l})$ & $2.8 \pm 0.21$ & $2.2 \pm 0.17$ & $1.5 \pm 0.15$ \\
\hline Monocyte $(\mathrm{x} 103 / \mu \mathrm{l})$ & $0.26 \pm 0.03$ & $0.11 \pm 0.01$ & $0.10 \pm 0.01$ \\
\hline E-rosette count & $14.20 \pm 3.2$ & $13.00 \pm 2.7$ & $10.01 \pm 2.2$ \\
\hline
\end{tabular}

Abbreviations: $\mathrm{MCV}$, mean corpuscular volume (MCV); MCHC, mean corpuscular hemoglobin concentration

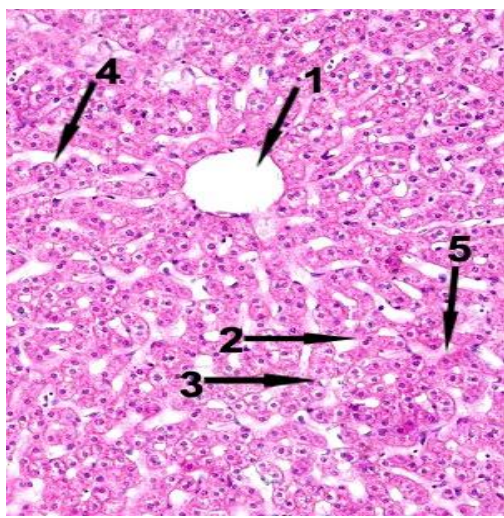

Control

H\& E, 40 X

Fig-1.1

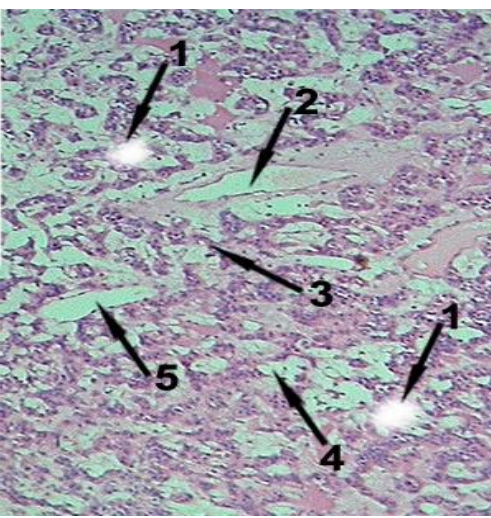

Low dose

$(50 \mathrm{mg} / \mathrm{kg} / \mathrm{b} . \mathrm{wt})$

H\& E, $400 \mathrm{X}$

Fig-1.2

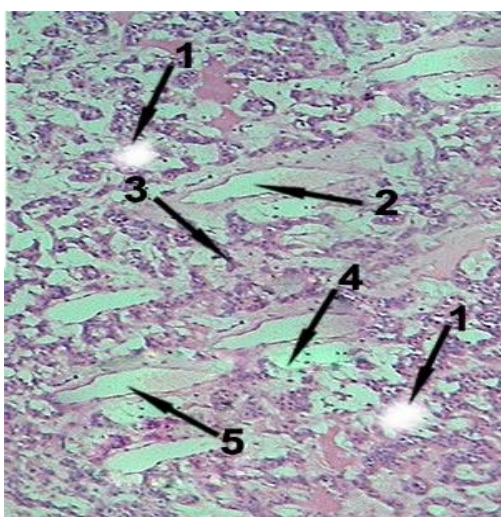

High dose

(500 mg/kg/b.wt)

H\& E, $400 X$

Fig-1.3

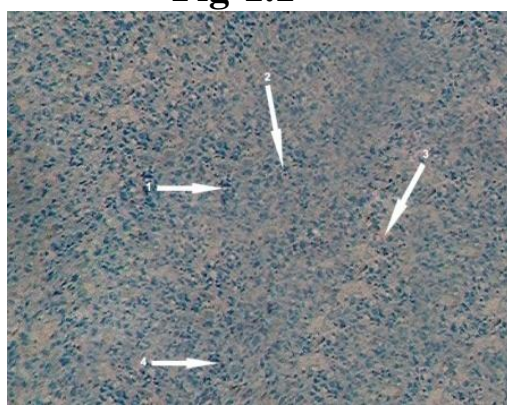

Control

H\& E, $40 \mathrm{X}$

Fig-2.1

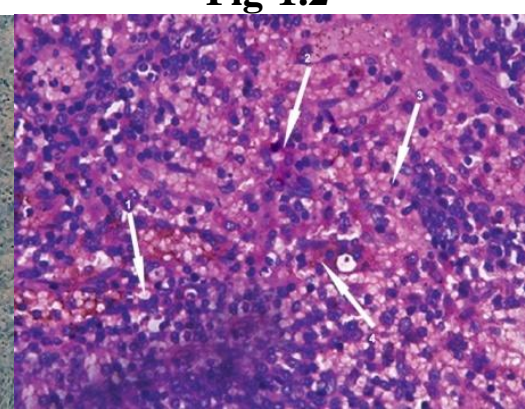

Low dose

(50 mg/kg/b.wt)

H\& E, $400 X$

Fig-2.2

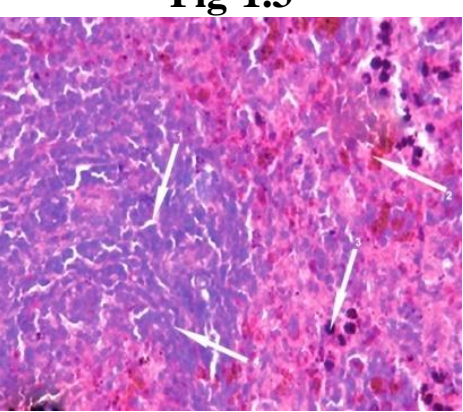

High dose

(500 mg/kg/b.wt)

H\& E, $400 \mathrm{X}$

Fig-2.3 
Int.J.Curr.Res.Aca.Rev.2016; 4(4): 110-120

Table.2 Biochemical Analysis of Serum Samples of Pregnant Rats in Control and BPA Groups

\begin{tabular}{|c|c|c|c|}
\hline Parameters & Control & BPA 50mg/kg & BPA 500mg/kg \\
\hline ALP (U/L) & $77.92 \pm 3.6$ & $257 \pm 11.54^{* * *}$ & $330 \pm 10.87 *$ \\
\hline Albumin (g/dl) & $2.16 \pm 0.08$ & $2.25 \pm 0.09$ & $3.34 \pm 0.05$ \\
\hline Globulin (g/dl) & $3.99 \pm 0.22$ & $4.17 \pm 0.09$ & $5.18 \pm 0.02$ \\
\hline A/G ratio & $0.62 \pm 0.06$ & $0.54 \pm 0.02$ & $0.25 \pm 0.09^{*}$ \\
\hline Glucose (mg/dl) & $121.7 \pm 6.4$ & $82.07 \pm 1.4^{* *}$ & $50.09 \pm 1.24^{* *}$ \\
\hline HDL (mg/dl) & $62.67 \pm 2.33$ & $62.00 \pm 5.5$ & $60 \pm 7.8$ \\
\hline LDL (mg/dl) & $59.46 \pm 2.8$ & $86.25 \pm 4.9 *$ & $102.54 \pm 4.8^{*}$ \\
\hline
\end{tabular}

Values are given as mean \pm SE. * significantly different from control group

In this study (histology) we observed diffuse lymphocytic hyperplasia and hypertrophy of lymphoid follicles as well as congested red pulp with hemosidrosis in the spleen of BPA treated pregnant rats \& control rats showed normal histological picture. Yoshino et al. (2004) reported that male mice treated with BPA at $3000 \mu \mathrm{g} / \mathrm{kg}$ bw/day had an enhanced lymphoid cell proliferation in response to hen egg lysozyme (HEL). Also, Youn et al. (2002) observed significant splenocytic proliferation in male mice treated with BPA for 4 weeks at drinking water at concentrations of $0.015,1.5 \mathrm{or} 30 \mathrm{mg} / \mathrm{ml}$. On other hand, BPA reported to induce a decline in the number of T-cells (Total, CD4 and CD8), B- cells and macrophages in the spleen (Sugita-Konishi, Y., et al., 2003).

Oral administration of BPA for 9 days in pregnant rats resulted anemia, in addition to alteration in several biochemical parameters that indicate liver and spleen injuries which confirmed with histopathological alteration those organs. During the critical phase of reproductive development, the fetus appears to be more sensitive than adults to endocrine disruption. This period is also considered crucial in animal's life. Since shaping of several hormonally regulated physiological processes happen and any interference at this period might lead to adverse consequences later in life. There are two principle reasons through which endocrine mimicking substances (BPA) may be more apparent on the developing fetus in this study, firstly the normal hormonal feedback homeostasis are under developed (Crisp et al., 1998) and secondly, poor affinity of these compounds towards sex hormone binding globulins, reduced haemoglobin cocentration which eventually leads to poor metabolism of these substances. Continued exposure of BPA during gestation of rat is likely to have an impact on the developmental trajectory of the fetus. Markey et al., (2002) reported that, Changes in uterine weights of pregnant rats is evident following developmental exposure to BPA may impact fertility, age of reproductive senescence and onset of disease later in life. Pregnancies complicated by intrauterine growth restriction are characterized by impaired placental blood flow, increased vascular resistance, and placental dysfunction reported by Krebs et al., (1996). Impaired placental blood flow with the associated reduced oxygen and nutrient delivery across the placenta to the fetus is one of the most common features of human pregnancies complicated by growth restriction. The present study provides evidence that BPA at $50 \mathrm{mg}, 500 \mathrm{mg} / \mathrm{kg}$ body wt/day was highly toxic to fetoplacental and uterine growth in early gestation of rats. 


\section{References}

Alonso-Magdalena, P., Morimoto, S., Ripoll, C., Fuentes, E., Nadal, A. 2006. The estrogenic effect of bisphenol A disrupts pancreatic betacell function in vivo and induces insulin resistance. Environ. Health Perspect, 114: 106-112.

Asahi, J., Kamo, H., Baba, R., Doi, Y., Yamashita, A., Murakami, D., Hanada, A., Hirano, T. 2010. Bisphenol A induces endoplasmic reticulum stress-associated apoptosis in mouse non-parenchymal hepatocytes. Life Sci., 87: 431-438.

Ben-Jonathan, N., Hugo, E.R., Brandebourg, T.D. 2009. Effects of bisphenol- A on adipokine release from human adipose tissue: Implications for the metabolic syndrome. Mol. Cellular Endocrinol., 304: 49-54.

Colborn, T., vom Saal, F.S., Soto, A.M. 1993. Developmental effects of endocrine-disrupting chemicals in wildlife and humans. Environ. Health Perspect., 101: 378-384.

Crisp, T.M., Clegg, E.D., Cooper, R.L., Wood, W.P., Anderson, D.G., Baetcke, K.P., Hoffmann, J.L., Morrow, MS., Rodier, D.J., Schaeffer, J.E., Touart, L.W., Zeeman, M.G. and Patel, Y.M. 1998. Environmental endocrine disruption: an effects assessment and analysis. Environ. Health Perspect., 106, Suppl.1: 1156.

Daniela-Saveta, P., Bolfa, P., Bela, K., Vlase, L., Paltinean, R., Anca, P., Catoi, C., Cran, G., Loghin, F. 2014. Influence of GenistaTinctoria $\mathrm{L}$ or Methylparaben on Subchronic Toxicity of Bisphenol A in Rats. Biomed. Environ. Sci., 27: 85-96.

Dumas, B.T., Biggs, H.G. 1972. Standard Methods of Clinical Chemistry. Vol
7. Academic Press, New York, pp: 175.

Eshak, M.G., Osman, H.F. 2014. Biological Effects of Chitosan against Bisphenol-A Induced Endocrine Toxicity and Androgen Receptor Gene Expression Changes in Male Rats. Int. J. Pharma. Clin. Res., 6(4): 300-311.

Fernandez, M.F., Arrebola, J.P., Taoufiki, J., Navalon, A., Ballesteros, O., Pulgar, R., Vilchez, J.L. and Olea N. 2007. Bisphenol-A and chlorinated derivatives in adipose tissue of women. Reproductive Toxicol., 24: 259-264.

Henderson, A.R., Moss, D.W. 2005. Tietz fundamentals of clinical chemistry. In: Burtis, C.A. Ashwood, E.R. (Eds.), Enzymes. Lubbok, Texas, pp: 352-390.

Hung, A.L., Lloyd, S. 1989. Role of the spleen and rosette-formation response in experimental eperythrozoon ovis infection. Vet. Parasitol., 32: 119126.

Kersten, S. 2001. Mechanisms of nutritional and hormonal regulation of lipogenesis. EMBO Rep., 2: 282-286.

Korkmaz, A., Ahbab, M.A., Kolankaya, D., Barlas, N. 2010. Infiuence of vitamin $\mathrm{C}$ on bisphenol A, nonylphenol and octylphenol induced oxidative damages in liver of male rats," Food and Chem. Toxicol., 48(10): 28652871.

Kotzka, J., Lehr, S., Roth, G., Avci, H., Knebel, B., Muller-Wieland, D. 2004. Insulin-activated Erk-mitogenactivated protein kinases phosphorylate sterol regulatory element-binding protein-2 at serine residues 432 and 455 in vivo. J. Biol. Chem., 279: 22404-22411.

Krebs, C., Macara, L.M., Leiser, R., Bowman, A.W., Greer, I.A. and 
Kingdom, J.C.P. 1996. Intrauterine growth restriction with absent enddiastolic flow velocity in the umbilical artery is associated with maldevelopment of the placental terminal villous tree. Am J Obstet Gynecol., 175: 1534-1542.

Markey, C.M., Rubin, B.S., Soto, A.M., Sonnenschein, C. 2002. Endocrine disruptors: from Wingspread to environmental developmental biology. J. Steroid Biochem. Mol. Biol., 83: 235-244.

Marmugi, A., Ducheix, S., Lasserre, F., Polizzi, A., Paris, A., Priymenko, N., Bertrand Michel, J., Pineau, T., Guillou, H., Martin, P.G. 2012. Low doses of bisphenol A induce gene expression related to lipid synthesis and trigger triglyceride accumulation in adult mouse liver. Hepatol., 55: 395-407.

Nadal, A., Alonso-Magdalena, P., Soriano, S., Quesada, I., Ropero, A.B. 2009. The pancreatic beta-cell as a target of estrogens and xenoestrogens: implications for blood glucose homeostasis and diabetes. Mol. Cell. Endocrinol., 304: 63-68.

Naito, H.K. 1984b. High-density lipoprotein (HDL) cholesterol. Kaplan A. Clin Chem. The C. V. Mosby Co St. Louis, Toronto Princeton, 1207-1213 and 437.

Newbold, R.R., Jefferson, W.N., PadillaBanks, E. 2009. Prenatal exposure to bisphenol A at environmentally relevant doses adversely affects the murine female reproductive tract later in life. Environ. Health Perspect., 117: 879-885.

Richter, C.A., Birnbaum, L.S., Farabollini, F., Newbold, R.R., Rubin, B.S., Talsness, C.E, Vandenbergh, J.G., Walser-Kuntz, D.R., vom Saal, F.S.V. 2007. In vivo effects of bisphenol A in laboratory rodent studies. Reprod Toxicol., 24: 131-138.

Sugita-Konishi, Y., Shimura, S., Nishikawa, T., Sunage, F., Naito, H., Suzuki, Y. 2003. "Effect of bisphernol-A on nonspecific immunodefense against non pathogenic Escherichia coli. Toxicol. Lett., 136: 217.

Takahashi, O., Oishi, S. 2000. Disposition of orally administered 2,2-Bis(4hydroxyphenyl)propane (Bisphenol A) in pregnant rats and the placental transfer to fetuses. Environ. Health Perspect., 108: 931-5.

Tamiya, T., Kashiwagi, I., Takahashi, R., Yasukawa, H., Yoshimura, A. 2011. Suppressors of cytokine signaling (SOCS) proteins and JAK/STAT pathways: regulation of T-cell inflammation by SOCS1 and SOCS3. Arteriosclerosis, thrombosis, and Vascular Biol., 31: 980-985.

Trinder, P. 1969. Determination of blood glucose using 4-amino phenazone as oxygen acceptor. J. Clin. Pathol., 22(2): 246.

Xie, X.H., Liao, H., Dang, W., Pang, Y., Guan, X., Wang, Y., Johan, J., Shyy, Y., Zhu, F.M. Saldek. 2009. Downregulation of hepatic HNF4alpha gene expression during hyperinsulinemia via SREBPs. Mol. Endocrinol., 23: 434-443.

Yamashita, U., Sugiura, T., Yoshida, Y., Kuroda, E. 2003. Effect of endocrine disrupters on thymocytes invitro. $J$. UOEH, 25: 161-170.

Yoshino, S., Yamaki, K., Li, X., Sai, T., Yanagisawa, R., Takano, H., Taneda, S., Hayashi, H., Mori, Y. 2004. "Prenatal exposure to bisphenol A upregulates immune responses, including $\mathrm{T}$ helper 1 and $\mathrm{T}$ helper 2 responses, in mice. Immunol., 112: 489. 
Youn, J.Y., Park, H.Y., Lee, J.W., Jung, I.O., Choi, K.H., Kim, K., Cho, K.H. 2002. Evaluation of the immune response following exposure of mice to bisphenol A: induction of Th1 cytokine and prolactin by BPA exposure in the mouse spleen cells." Arch. Pharma. Res., 25: 946.

Zumbado, M., Boada, L.D., Torres, S., Monterde, J.G., Diaz-Chico, B.N., Afonso, J.L., Cabrera, J.J., Blanco, A. 2002. Evaluation of acute hepatotoxic effects exerted by environmental estrogens nonylphenol and 4octylphenol in immature male rats. Toxicol., 175: 49-62.

Zumbado, M., Boada, L.D., Torres, S., Monterde, J.G., Diaz-Chico, B.N., Afonso, J.L., Cabrera, J.J., Blanco, A. 2002. Evaluation of acute hepatotoxic effects exerted by environmental estrogens nonylphenol and 4octylphenol in immature male rats. Toxicol., 175: 49-62.

\section{How to cite this article:}

Geetharathan, T., 2016. Hematological, Biochemical and Histopathological Changes by Bisphenol-A in Albino Pregnant Rats. Int.J.Curr.Res.Aca.Rev.4(4): 110-120. doi: http://dx.doi.org/10.20546/ijcrar.2016.404.013 